\title{
12 Co-creating policies on societal transformations as a factor of resilience of modern society
}

\author{
Nadejda Komendantova, Sonata Neumueller and \\ Elvis Modikela Nkoana
}

\section{Introduction}

International climate policy settled targets to mitigate impacts of climate change through decarbonization of various sectors of national economies, such as energy generation, mobility or housing (IPCC, 2019). Energy sector contributes a significant share of greenhouse gas emissions, therefore various goals were settled to decarbonize energy and electricity generation, even up to $100 \%$ by the year 2050 . Renewable energy sources (RES) are one of the possible options to decarbonize electricity generation (Patt, 2015). RES is also considered by energy security policies as an option to satisfy energy demand with locally available energy resources and to mitigate the risks connected with volatility of energy supply from other countries (European Commission, 2014).

Deployment of RES at scale will lead to societal transformation and to the transformation of energy systems, including all its parts such as energy generation, transmission and distribution. It will lead to a transition from centralized energy solutions based on large-scale fossil fuel energy generation power plants to more decentralized solutions based on diversified RES such as solar, wind, geothermal and others. Electricity transmission and distribution grids, including high direct voltage grids and smart grids, will be playing a greater role to balance RES that are in various places or to cover intermittency in energy supply and demand.

This process of societal change based on the transformation of energy systems is termed "energy transition" within mainstream energy policy making processes (Sovacool, 2016). This "energy transition" is deemed a wicked process as it involves many stakeholders with their various and sometimes conflicting interests, perspectives and aims (Komendantova, 2018). Therefore, understanding the positions of various stakeholders and development of common-ground policy-oriented options is crucial (Komendantova et al., 2018).

As such, the public are an important stakeholder and an end-user of services in the energy transition hence it is crucial to understand patterns of public acceptance of energy transition process. It is within this context that we should understand that the transition towards a more sustainable energy system will require not only the implementation of technological solutions but also a change in behavior of people with respect to the growing use of RES. Laypeople need to be at the 
center of the energy system; they need to be informed, engaged and activated. Laypeople also have the right to participate in decision-making processes that affect their lives (Nkoana et al., 2017). To this end, the objective of this chapter is to deepen our understanding of behavior and motivation structures within the complexity of different user groups in the energy transition process by reporting on empirical case studies conducted in two regions in Austria. Hopefully, the lessons learnt in this region might inform policy and practice in the countries of the Baltic Sea Region (BSR).

\section{Background}

Energy transition is giving a greater focus to the local level of governance. In many European countries, there are targets of energy transition that are settled at the regional and national level but are being implemented at the local level (REN 21, 2019). For example, in Austria, the targets of climate policy and energy security are identified by the Federal Government. This includes targets on decarbonization of energy generation, transportation, housing sector and industry. These targets are implemented in frames of the Climate and Energy Model regions (CEM) or at the level of various cities (Komendantova and Neumueller, 2020). The Climate and Energy Model regions are regions in Austria which took commitment towards a high share of RES, up to $100 \%$, in their energy mix. Austria is pursuing its climate goal and concurrently energy security and regional development, by supporting CEM regions, which are committed to becoming independent of fossil fuels by 2050 (Climate and Energy Fund, 2014).

In the past two decades, discussion about energy transition was going in frames of the so-called Not-in-My-Backyard (NIMBY) thinking and was criticized later in social sciences (see, for example, Burningham, 2000; Wolsink, 2006). NIMBY was even a special term that was developed to describe issues with public acceptance in communities where energy infrastructure was planned. The meaning of this term is that there are globally recognized goals such as the need for climate change mitigation. These goals should be implemented in communities because infrastructure should be constructed somewhere. Inhabitants of these communities are supporting such goals in general but are reluctant to have infrastructure in their communities (Kaldellis et al., 2013). Now the discussion about energy transition is considering NIMBY thinking more and more as a pejorative description of legitimate interests of communities regarding infrastructure that will affect their lives (Wolsink, 2012). Nowadays, local communities are also frequently questioning the necessity of deployment of large-scale infrastructure to address global problems such as climate change (Wüstenhagen et al., 2007) considering other available alternatives such as decentralized energy generation (Wolsink, 2000).

Today the communities' attitude towards energy infrastructure is changing in comparison to the situation of the last century when the backbone of the existing energy infrastructure was constructed (Komendantova et al., 2018). Before, 
energy infrastructure was considered as some kind of "economy locomotive" that was a driver for technological and economic development. Nowadays, there is a growing perception of impacts from such infrastructure on human health and environment. Such perceptions were formed by the growing awareness after several technological accidents such as Chernobyl and Fukushima.

Also, several international declarations, scientific results and awareness campaigns by environmental and social groups have changed the understanding of local communities from being passive recipients in the implementation of decisions made at the national governance level delivered by the so-called "experts" to a more participatory governance wherein communities have a right to express their views regarding infrastructure projects that affect their lives and livelihoods. The Universal Declaration of Human Rights calls for participation of people in decision-making processes that affect their lives (Zillman et al., 2002). Participation of local communities in decision-making processes can also increase the quality of outcome as the knowledge available to experts and decision-makers at the national level might be limited and the inclusion of local knowledge can be essential (Nkoana et al., 2017; Rowe and Frewer, 2000).

Participation of local communities in decision-making processes goes beyond simple social acceptance of energy infrastructure. Usually the term "acceptance" applies to lay people or affected communities when there is opposition to the planned infrastructure. Acceptance in favor of the projects was studied much less frequently (Cohen et al., 2014; Wolsink, 2012). Also, the term "acceptance" relates to tolerating something that is impossible to change (Batel et al., 2013). It is also a part of top-down decision-making process when acceptance from inhabitants is needed to construct projects, decisions about which are taken at the national level, without public protests at the local level (Rau et al., 2012).

Participation of local communities and integration of views of laypeople can increase legitimacy and trust in decision-making processes which usually would have been in the hands of "educated experts" (Nkoana et al., 2017; Renn, 2008). In a traditional decision-making process, information and knowledge flows from scientific experts, practitioners and policymakers at the national level to stakeholders at the local governance level. Frequently, such decisions are communicated to the public in a form of decide-announce-defend (DAD) model. However, such an expert-driven process often does not consider the complex relationship between experts and the public and can even lead to the loss of trust in public institutions by laypeople. The shortcoming of this process calls for greater public participation in decision-making processes that affect communities and the way of life of such people (Renn, 2015). Participatory governance goes beyond this model as it is based on the procedural, normativity and substantive principles of participation. Participatory governance is also defined through these principles. Normativity is based on a democratic principle, which states that citizens should be involved in decision-making processes. Engaging citizens in decision-making processes can lead to empowerment, equity and equality. Substantive principle argues that the involvement of citizens improves the quality of decision-making process and outcomes. Broader participation facilitates access to diverse, 
extensive and context-specific knowledge and takes a more careful and explicit account of divergent values and interests. In turn, this approach fosters collaborative or social learning. Instrumental imperatives foster the acceptability and justification of decisions. It states that citizens are more likely to accept an outcome if they took part in the decision-making process (Salter et al., 2010). In addition, the output justice that involves principles of transparency of information and its availability as well as engagement of stakeholders at various levels, including the local one, and discussion about fair distribution of risks, costs and benefits of the project. Therefore, participatory governance can not only increase the quality of decision-making outcomes but also contribute to implementation of good governance practices and democratic processes.

\section{Methodology}

Our research is focused on two case studies, namely, Freistadt and Amstetten, where we conducted our research in the period between 2015 and 2020. Freistadt is in the northern part of Upper Austria and has 27 municipalities. Agricultural land constitutes the biggest part of the region (53\%) while forests account for $42 \%$ of it. The economy of the region is dominated by small-scale companies, which are mainly one-person operations. The major challenge to the region is the high rate of commuters (29\%) needing to travel to Linz for employment. Freistadt established the ambitious goal of reaching the highest possible rate of energy self-sufficiency based on renewable energy sources. The region is home to one of the biggest solar power stations in Austria, which is financed by local people. There are also several local initiatives promoting renewable energy sources. These initiatives are managing the implementation of the targets of the CEM concept. To date, they have already implemented 30 district heating facilities, five biogas plants and some small-scale hydropower plants.

The Amstetten South CEM region has 19 municipalities and is an industrial region in the Ybbstal Valley in the Alpine foothills. The region has around 58,000 inhabitants and rural areas especially in the south. The region is well connected to all commercial centers with a highway.

RES is considered useful in both regions (Amstetten and Freistadt) because there are ample potential resources there such as solar panels and hydropower (Komendantova and Neumueller, 2020). Among renewable energy sources, the region is especially promoting small hydropower stations due to the abundance of water resources in the region. The programs of energy transition include implementation of energy efficiency measures, especially in the real estate, construction and housing sectors. The importance of electro-mobility is also growing. Public information measures include raising awareness through personal communication, community meetings and media reports.

This research deals with human factors of energy transition, such as the drivers to support or oppose the energy transition. It used a mixed method approach that included both quantitative and qualitative data collection techniques through key informant interviews, observation of stakeholders' events and a standardized 
survey questionnaire distributed among inhabitants of the case study regions. In total, 4,500 paper questionnaires were sent out to the population in the CEM region of Freistadt and the response rate was 7\%. In total, 30,000 questionnaires were sent out to the population in the CEM region in Amstetten and the response rate was low at $1.2 \%$.

In Freistadt, the heads of offices of 25 municipalities were contacted by phone to request their participation in the survey. Seventeen municipalities agreed to participate in the research and eight municipalities refused. The reason for their refusal was the lack of time and personnel resources. In the CEM region of Amstetten Süd, the survey questionnaire was sent out as an attachment of the regional newspaper "locum Mostviertel" in all 19 municipalities. Consequently, we contacted the municipalities and informed them about the project and the questionnaire and asked them to collect the filled in questionnaires. Furthermore, we convinced most of the municipalities to place the link to the questionnaire on their homepage and promote the project actively within their municipalities. As in the CEM region Freistadt, we stayed in contact to keep an overview as well as to assist with problems concerning the course of the project. In total, 240 Web interviews in the CEM region of Amstetten and $322 \mathrm{Web}$ interviews in the region of Freistadt were collected. Several 354 mailed-out questionnaires were returned from Amstetten and 316 from Freistadt respectively. Based on these figures, we calculated the number of questionnaires required to fill the sample quota for each region. As a result, in the first week of January 2016, we planned a field trip to the two CEM regions. A team of five interviewers and a research manager travelled to Freistadt and then to Amstetten to complete the task of augmenting the questionnaires quota. The field phase was scheduled for five days and during this time, the team collected completed questionnaires in the municipal offices that were not returned to the researchers' office so far. A comprehensive sampling was developed prior to the data collection. According to this sampling, interviewers approached the missing social groups in the sampling. In addition, to augment the self-completed questionnaires distributed in the survey via mail and web, the team of researchers interviewed respondents using the survey questionnaire to fill-in the required quota. During this field trip, the research team visited five municipalities and collected another 369 questionnaires completed through face-to-face interviews. So, the total number of respondents in the survey is 1601 (see Table 12.1). The representation of respondents was equal according to the

Table 12.1 Number of completed questionnaires in Amstetten and Freistadt.

\begin{tabular}{lccc}
\hline & Amstetten & Freistadt & Total \\
\hline Mail out & 354 & 316 & 670 \\
Web & 240 & 322 & 562 \\
Face-to-face & 207 & 162 & 369 \\
Total & 801 & 800 & 1601 \\
\hline
\end{tabular}


number of male and female respondents. Various age groups were also represented equally. The sampling included respondents with various levels of education, from the basic to the university one. In results where we saw that education played a significant role, we weighted the results according to the percentage of people from this education group in the overall sampling.

Interviews and questionnaires were analyzed with the help of artificial intelligence methods such as various methods of content analysis, including NVivo and Atlas.ti. The data were analyzed with various methods of statistical analysis including correlations and linear regressions analysis. Correlation analysis relates to the regression analysis which is a statistical approach to model associations between dependent variables and provide explanatory of independent variables. Finally, we conducted a validation workshop with CEM managers of the identified regions as well as from other CEM regions to discuss our results and their implementation in the energy policy process.

\section{Results}

\section{Awareness about renewable energy sources}

Our results show the level of public awareness about climate change mitigation among Austrian inhabitants as well as their willingness to support RES. The inhabitants of both regions are aware of climate change. For instance, over $90 \%$ of respondents in Amstetten and Freistadt believe that climate change is happening and it is caused by man-made activities. Even though the many respondents believe that climate change is real, their understanding of the causes of climate change varies according to their occupation. Considering the occupation variable, farmers seemed less convinced that climate change is mostly caused by human activities than it is by natural variability in the climate. Farmers' perceptions of the causes of climate change were closely followed by those of the unemployed respondents' who unequivocally indicated that climate change is a result of natural variability instead of anthropogenic activities.

Many inhabitants in Freistadt and Amstetten, where we conducted large-scale surveys, think that development of renewable energy sources is the best climate change mitigation option (see Figure 12.1 and Figure 12.2). Being aware about climate change, the majority of inhabitants' support climate change mitigation, such as deployment of renewable energy sources or implementation of energy efficiency measures. However, the biggest part of inhabitants is completely against nuclear energy. For instance, $61 \%$ of respondents in the CEM regions support the deployment of RES as an applicable climate change mitigation strategy, 54\% are in favor of increasing efficiency in the production and storage of energy, 51\% supports the reduction of energy needs, $46 \%$ prefers limiting emissions from existing power stations. Overwhelmingly, more than $70 \%$ of the respondents rejected nuclear as a potential energy source in both regions of Amstetten and Freistadt.

The comparison of both regions showed that there is almost no difference in preferences regarding climate change mitigation options among inhabitants of 


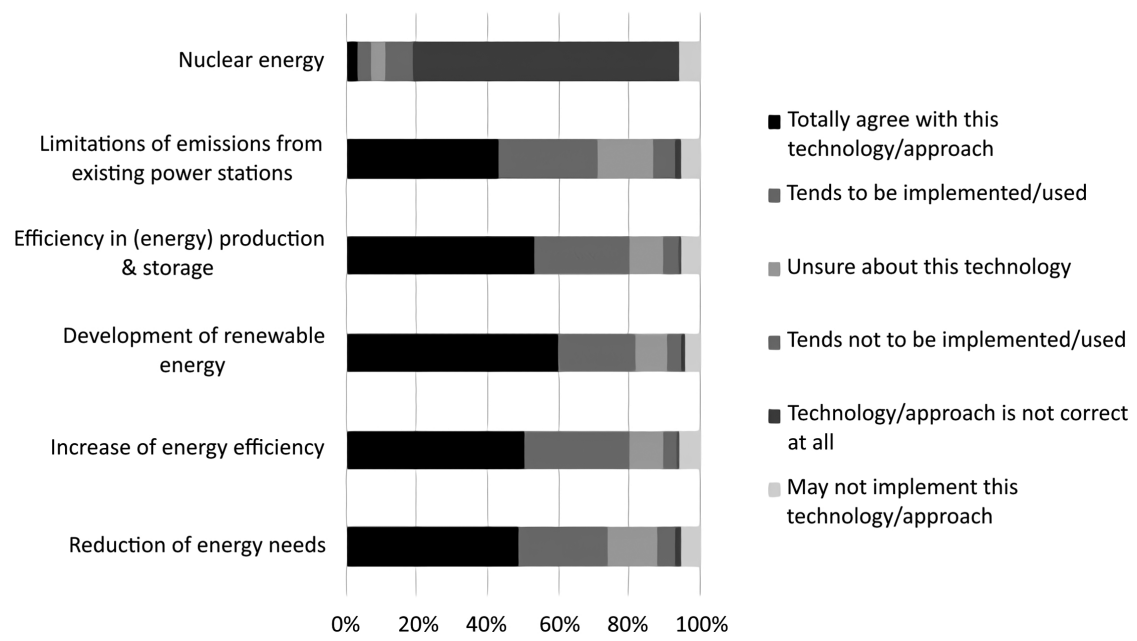

Figure 12.1 Preferred climate change mitigation options in Freistadt.

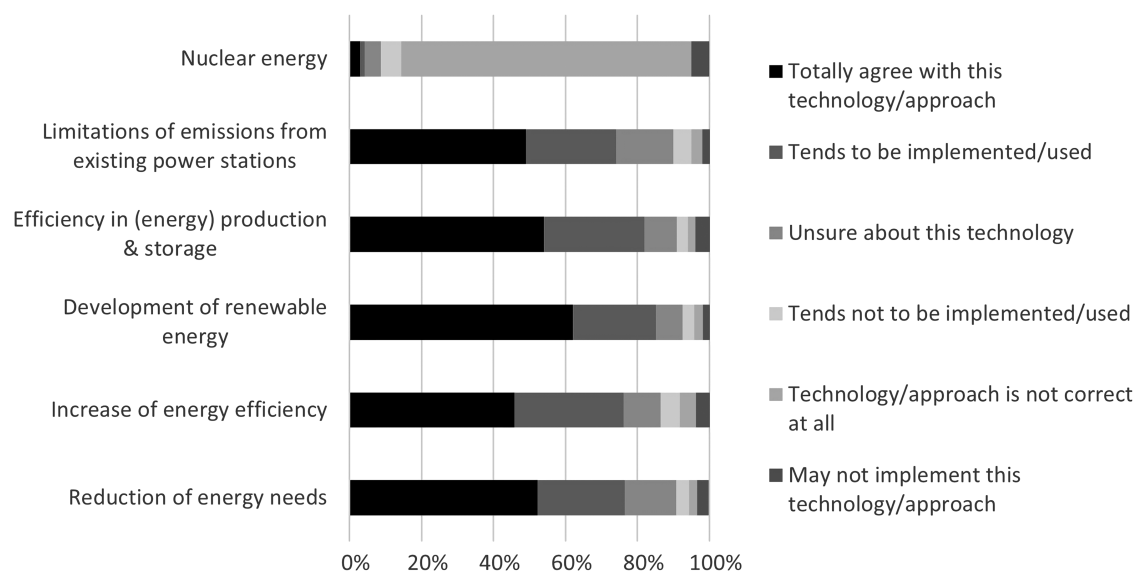

Figure 12.2 Preferred climate change mitigation options in Amstetten.

these regions. Inhabitants of both regions totally reject nuclear power and have RES as preferred options.

Over $60 \%$ of respondents were aware of measures aimed at deploying renewable energy technologies and mechanisms in their local communities but $40 \%$ were unaware of this initiative. The $40 \%$ represents a sizeable number of residents $(n=727)$, which are unaware of renewable energy transitions in their immediate communities, revealing the inadequate information (communication) in the CEM regions initiative. Despite this, respondents unanimously endorsed renewable energy projects as bearing positive benefits in their regions. Knowledge of 
the CEM regions by lay people can facilitate the public's acceptance of renewable energy transition.

Despite being well informed about climate change, its mitigation and available options, inhabitants are less informed about implementation of these options, namely, in frames of the CEM process. We found that $36 \%$ of the respondents do not know about the CEM regions initiative and 46\% have heard about it but do not have sufficient information about its implementation. Only 17\% of the respondents confirmed their thorough knowledge of the CEM regions initiative. We discovered that pensioners and middle-aged professionals possessed more information about the CEM regions initiation. What is mostly concerning is that only $3 \%$ of the youth had a thorough knowledge about the CEM regions, with over $40 \%$ having heard about the initiative, and more than $50 \%$ had never heard of the energy transition endeavor.

Nearly half of the respondents are unaware that their community is participating in the CEM initiative. We further segregated the primary data by occupation and found that most workers, employees, students, self-employed and unemployed residents did not know that their communities are participating in the CEM process. On the contrary, pensioners and farmers were well informed about their local communities participating in the CEM process.

While speaking about policy processes like energy transition, there is a great variety in the level of awareness among inhabitants. Many people over 61 years old in both regions $(61 \%)$ know about CEM regions as a vehicle to implement the energy transition policy in Austria. However, the level of awareness decreases with the age of respondents. Young people below 20 years old are the least informed group of inhabitants. In comparison, around $50 \%$ of all respondents aged over 61 years showed awareness and knowledge about participation of their community in the CEM process. Only around 18\% of the youth had this awareness and knowledge. In general, the level of awareness among inhabitants of Freistadt was higher than their counterparts in Amstetten. As such, inhabitants from Freistadt in the age between 41 and 60 were the best-informed group of population (see Figure 12.3).

Access to information from various media sources might play a role in awareness, as such, respondents receive information on regional energy transitions from a mixture of traditional and new media that include the internet, television, radio and newspapers. We subsequently investigated the correlation between the type of information source and education level of the respondents. The results show that varying educational attainment also influences the preference of an information source. For example, respondents with university degrees received some of the information on regional energy transitions from scientific publications. Also, these university educated respondents used a variety of information sources rather than soliciting a few. On the contrary, respondents with primary and secondary education relied on a limited source of information about regional energy transitions, with their information mainly coming from family and/or friends, private companies which implement RES projects and local NGOs. 


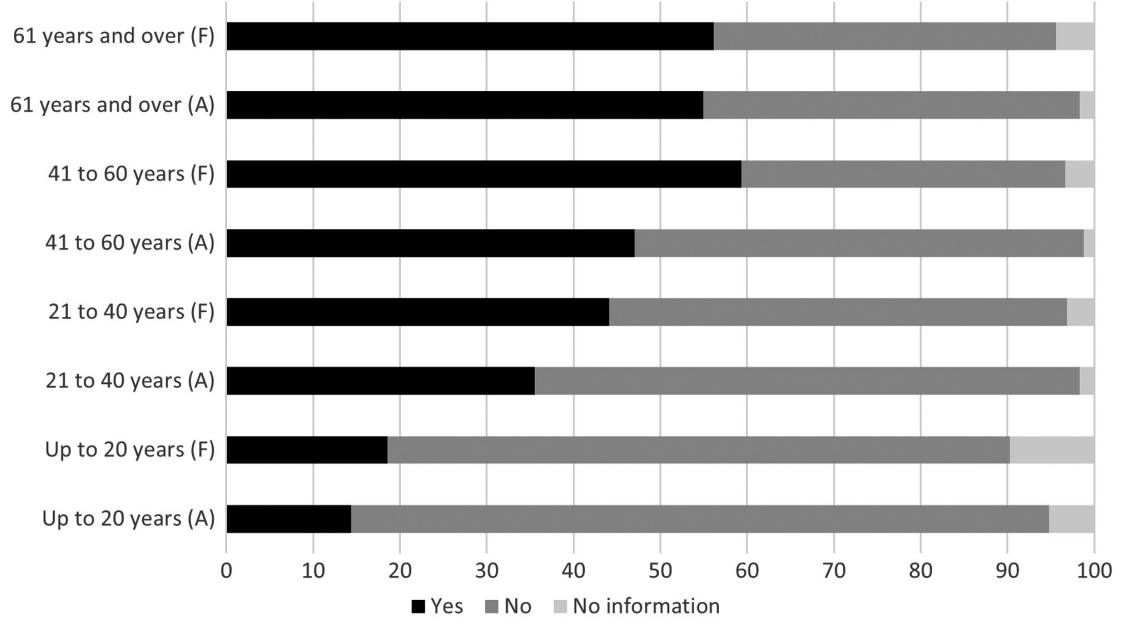

Figure 12.3 Level of awareness among inhabitants of Freistadt (F) and Amstetten (A) about participation of their community in the CEM regions initiative. "No information" option means that the respondent could not provide the answer.

Many inhabitants of both regions receive their information about energy transition from various media such as TV, radio, newspapers and internet. The influence of other sources such as NGOs, private companies, scientific publications, friends and family is much lower. Local authorities are the second most influential source of information after media (see Figure 12.4).

\section{Support for the deployment of renewable energy sources}

Many inhabitants in both regions support the deployment of RES. However, this support varies significantly depends on the technology such as wind energy, geothermal, solar power or biogas. In general, solar power enjoys the highest level of support, followed by geothermal and hydropower. Biogas is the least preferable option. Support for wind energy and biomass is also significantly lower in comparison to other renewable energy sources (see Figure 12.5).

The usage of renewable energy sources depends strongly on the size of a household with general tendency - the larger the household is, the greater is the willingness to use RES. There are different explanations for this finding. This willingness might relate to the fact that larger households have children. Such households care more for the environment because they are concerned about the future of their children. They might also consider installation of PV because they think that this might help to reduce electricity costs or to make them more independent from energy suppliers. Or it might also relate to the fact that larger households live mainly in privately owned houses and not rental apartments. The fact that someone lives in a private house increases the willingness to use renewable energy sources because such investment belongs to the person. In rental apartments, there is no incentive to make private investments from the site of the 


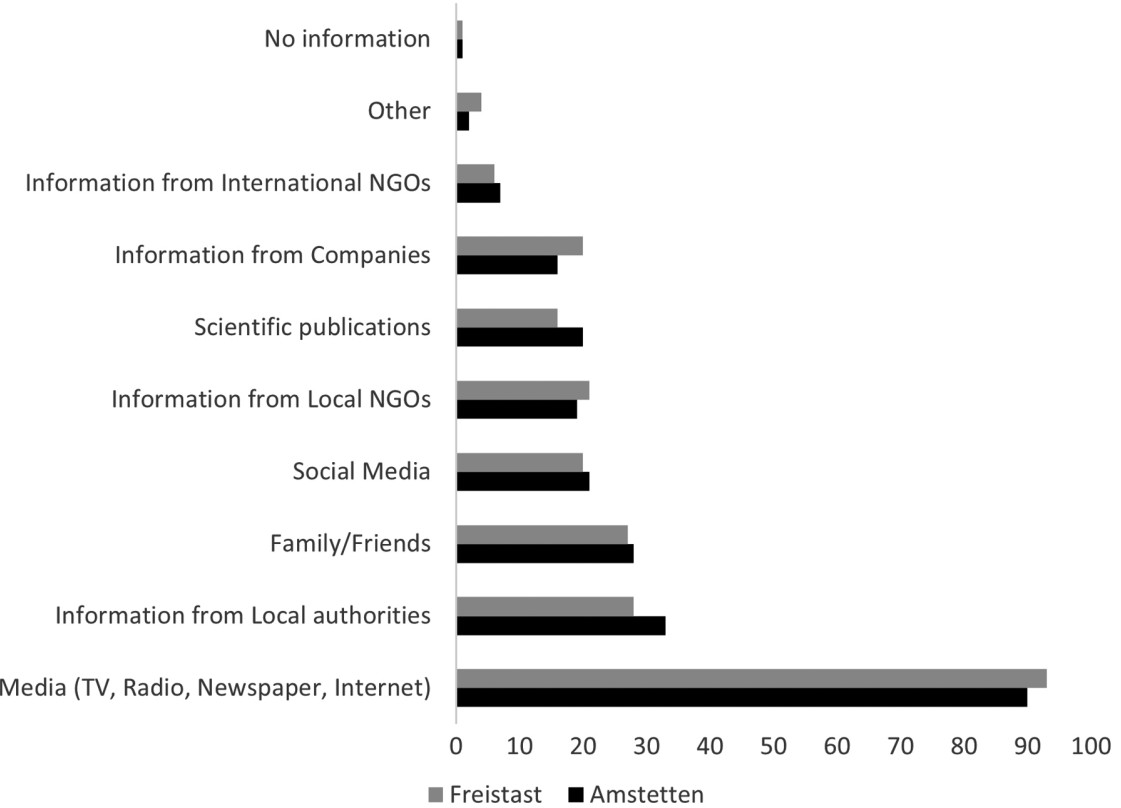

Figure 12.4 Sources of information about energy transition in Freistadt and Amstetten. "No information" option means that the respondent could not provide the answer.

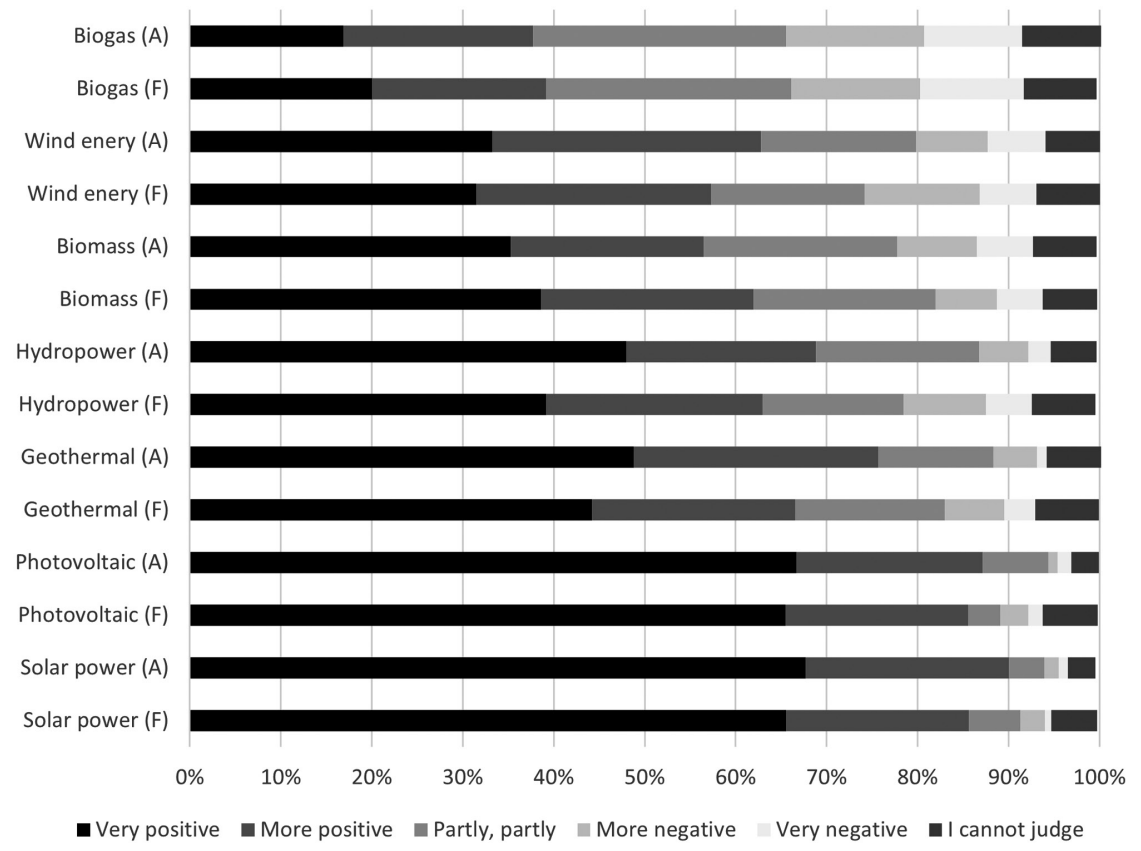

Figure 12.5 Attitudes towards renewable energy sources in Freistadt (F) and Amstetten (A) (partly means here "undecided"). 
tenant. However, investigation of this phenomena with other factors was beyond the scope of our research.

Our results show a significant share of households made of one person is not using renewable energy sources. At the same time, the share of households who are not using renewable energy sources among five-person households is much lower and a bigger part of these households are using up to $50 \%$ of renewable energy sources to cover their energy needs. A significant share of households is covering more than $75 \%$ of their energy needs from renewable energy sources. Interestingly, the number of such households in Freistadt is almost twice as high as in Amstetten.

The Willingness-To-Pay (WTP) for renewable energy sources also depends on the kind of economic activity exercised by the respondent. Our results show that WTP is the lowest among unemployed people with most of them wishing no additional payment for renewable energy sources. But the results for this group are also polarized. A significant share of unemployed people would be willing to pay between $21 \%$ and $30 \%$ more for renewable energy sources.

On average, people are happy to pay up to $10 \%$ more for energy that comes from renewable energy sources. The group of students in Freistadt would be willing to pay between $11 \%$ and $20 \%$ more for renewable energy sources. The second strongest group of people that is willing to pay up to $30 \%$ more for renewable

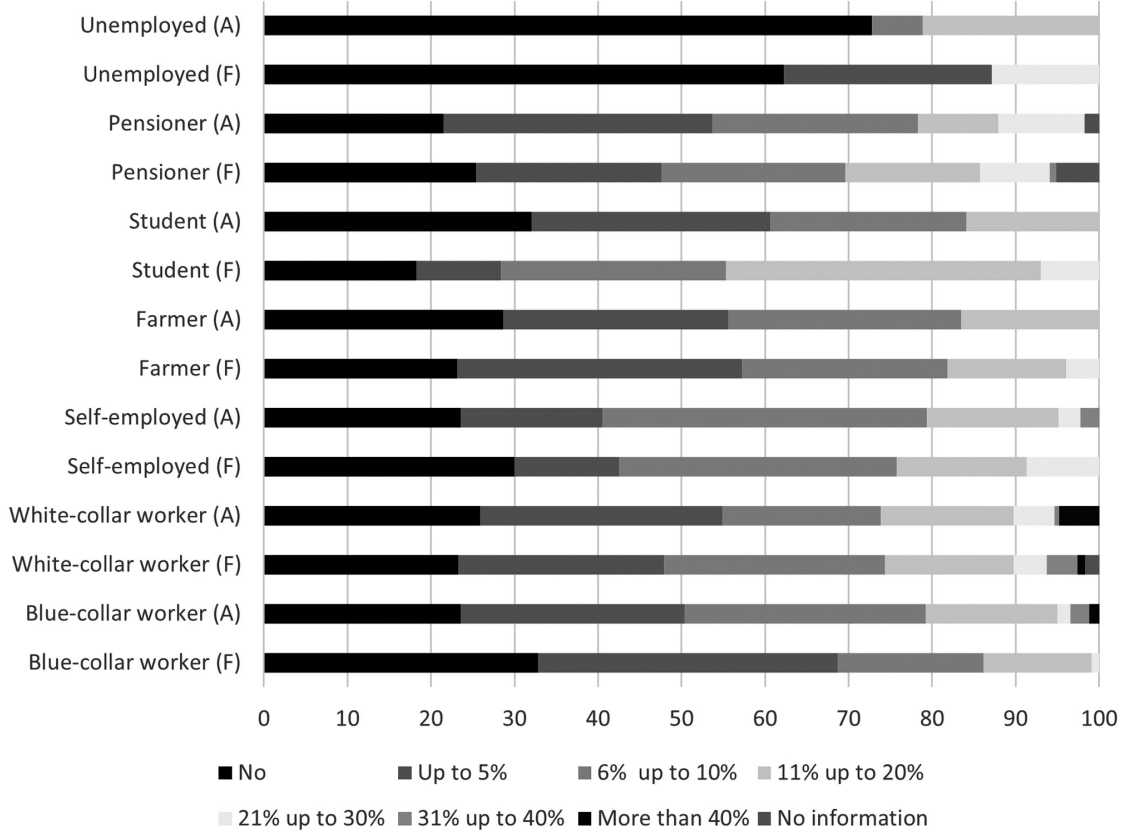

Figure 12.6 Willingness to pay for renewable energy sources among inhabitants in Freistadt (F) and Amstetten (A). The answer "no information" means that the respondent did not know what to answer. 
energy sources are pensioners in both regions. Also, among self-employed people in Freistadt, the share of people willing to pay up to $30 \%$ for renewable energy sources is significant (Figure 12.6).

\section{Discussion and recommendations}

\section{Discussion of results}

Our results show that an overwhelming majority, over $90 \%$, of the respondents in the CEM regions of Freistadt and Amstetten believe that climate change is a real phenomenon. This result is supported by a comparative survey study of climate change perceptions of residents in the European Union (EU) and in the United States conducted by Lorenzoni and Pidgeon (2006). However, and despite this heightened level of awareness, residents in both regions have different understanding of the causes of climate change due to their varied demographic variables such as occupation. For example, most respondents indicated that climate change is caused by man-made activities. However, farmers were less convinced that climate change is caused by man-made activities more that it is induced by natural variability. This is baffling as studies report that farmers have high levels of awareness and perceptions of climate change due to their intimate relationship to the ecological environment through the land they cultivate (Fosu-Mensah et al., 2012; Deressa et al., 2011; Manandhar et al., 2011; Gbetibouo, 2009; Mertz et al., 2009; Maddison, 2007). Farmers' views were closely shared by the unemployed residents who strongly believed that climate change is caused by natural variability instead of anthropogenic factors.

Despite this, residents' high levels of awareness about the causes of climate change seems to factor into their support for the deployment of renewable energy technologies in their region.

With nearly two-thirds of the respondents aware that their regions are transitioning away from fossil fuels towards renewable energies with only one-third responding otherwise. Interestingly, respondents in the Freistadt region seem to know more about regional energy transitions than their counterparts in Amstetten. Of concern is that one-third (36\%) of the respondents did not know that their region is transitioning away from fossil fuels towards renewable energy sources in both regions. This large percentage of uninformed residents in this study is concerning considering the public resistance to the deployment of renewable energy technologies experienced in Europe (Musall and Kuik, 2011; Jones and Eiser, 2010; Zografakis et al., 2010; Zoellner et al., 2008).

In this energy transition, respondents preferred the deployment of renewable energy technologies such as solar, wind and photovoltaic as popular choices, increasing energy efficiency through renovations of private and public buildings, and reducing energy needs using electric cars, and car sharing schemes.

The popularity of certain renewable energy technologies for electricity generation presents an entry point through which planners and decision-makers in the CEM regions initiatives can solicit the buy-in of residents into the energy 
transition effort. For example, over two-thirds of the respondents overwhelmingly supported the installation of solar energy technologies such as photovoltaics. With nearly one-third of the respondents supporting the deployment of hydropower, geothermal and biomass energy sources in their region. However, less than one-third of the respondents supported the utilization of wind energy and biogas in the CEM regions. The insignificant support for wind energy might be explained by NIMBYism attitude induced by residents' concerns over noise and visual pollution (Devine-Wright, 2014). Respondents' support of biogas is very low despite it being a renewable energy source. This might be due to smell perception, socio-economic factors and communication challenges reported in other regions. It is noteworthy that communication challenges remain a key theme that consistently re-emerges in this study. This challenge is reported in other parts of the world (see, for example, Ahlborg and Hammar, 2014; Richards, Noble and Belcher, 2012; Musall and Kuik, 2011; Mondal, Kamp and Pachova, 2010; Mirza et al., 2009; Sovacool, 2009).

On average, respondents in Freistadt seem better informed than their counterparts in Amstetten and this trend features prominently in our results. Pensioners and respondents between the ages of 41 to 60 years are more informed about energy products and energy transitions when compared with other age groups. Young people constitute most uninformed respondents. Once more, this trend draws attention to the inadequate involvement of young people in the CEM regions effort. In addition, over $60 \%$ of respondents were aware of measures aimed at deploying renewable energy technologies and mechanisms in their local communities and around $40 \%$ were unaware of such steps. This $40 \%$ represents a sizeable number of respondents $(n=727)$ that are unaware of renewable energy transitions in their immediate communities revealing the inadequate information-sharing.

\section{Implications for the BSR}

Our results on Austria allow us to develop the following recommendations for further deployment of renewable energy sources in the BSR where most of its countries are the EU member states as well. We identify here three groups of factors which should be considered while addressing attitudes of people towards RES in the countries of the BSR.

First, the level of awareness can be affected by the information-sharing and communication channels tailored to the varying age groups of the residents of energy transition regions. As a result, it is recommended to have targeted information campaigns for different groups of population as well as usage of targeted and trusted information channels.

Second, respondents seem to be much better informed about climate change and the need for its mitigation, in general. However, they are much less informed about details of the projects in their localities or about energy policy processes on energy transition in which their communities are participating. Therefore, it is recommended to diversify information campaigns from the focus on the need 
of climate change mitigation to more detailed information about projects and processes in the vicinity of people.

Third, the level of support for different kinds of renewable energy sources might be very different. In Austria, people are mostly supporting solar energy while biogas has the lowest level of support. Therefore, it is recommended to evaluate how inhabitants of local communities support various kinds of renewable energy sources rather than treating renewable energy sources as one category with the same level of support.

Last, the level of support varies significantly dependently on the kind of occupation, size of household and the age of the respondents. Therefore, it is recommended to identify the drivers of support among various groups of population and to develop and implement policy support measures that target these specific groups of population.

\section{Concluding remarks}

This study investigated the awareness of renewable energy sources and support for their deployment in a Western European country. Using empirical methods, we administered a survey questionnaire to more than 1,000 residents in the Freistadt and Amstetten regions of Austria. The primary data was analyzed using descriptive statistics and correlation analysis. We found that most residents in both regions are aware of the climate change phenomenon and the different types of renewable energy sources and technologies deployed for its mitigation. In addition, the residents overwhelmingly support the deployment of these renewable energy technologies in their regions.

The residents preferred solar energy more when compared to wind power. This should not come as a surprise as most European countries experienced a bush-back by residents through the so-called NIMBY stereotype against large wind farms. Interestingly though, was that residents preferred hydropower and geothermal sources more than wind power. Biogas, a renewable energy source, was the least preferred by the residents of the CEM regions. Nuclear power was completely rejected by the residents in both regions owing to the human health hazards and safety risks associated with it and in the context of widely reported Chernobyl and Fukushima disasters. Information on these nuclear accidents were widely publicized in all forms of media highlighting the importance of information-sharing and communication in a way.

Information-sharing is important in the energy transition, as a sizeable portion of the respondents were unaware of the initiative aimed at deploying renewable energy technologies in their region and the benefits thereof. The data analysis revealed that their ignorance was due to the limited communication they received from the authorities responsible for the energy transition. This is not surprising as scientific literature suggests that communication is an important factor in the transition from fossil fuels to renewable sources. More information campaigns using different media for varying social groups is urgently required to aid public acceptance that bolsters successful transition towards renewable 
energy sources. Targeted, clear and transparent information campaigns are also a first step on the way of engaging people into energy transition.

The BSR countries have good potentials for deployment of renewable energy sources but further work on addressing human factors of an energy transition is needed. Following recommendations from other regions, further research should evaluate the available level of acceptance and attitudes towards various potential RES in the BSR. This should include attitudes and preferences for various technologies but also for the process of energy transition itself. Also, further research is needed to evaluate how information about energy transition is being communicated to various social groups and what are the trusted sources of information. The communication messages should be tailor made to the needs of each social group and to the trusted communication channels. Further understanding is also needed on potentials for engagement into an energy transition, which possibilities exist already and into which parts of the decision-making processes people would like to be engaged.

\section{Acknowledgment}

This work has been partially funded by the Co-Inform project (770302), under the Horizon 2020 call "H2020-SC6-Co-Creation-2016-2017 (Co-Creation for Growth and Inclusion)" of the European Commission and by core funding of the International Institute for Applied Systems Analysis.

\section{References}

Ahlborg, H. and Hammar, L. (2014). Drivers and barriers to rural electrification in Tanzania and Mozambique-Grid-extension, off-grid, and renewable energy technologies. Renewable Energy, 61, Amsterdam: Elsevier, pp. 117-24.

Batel, S., Devine-Wright, P. and Tangeland, T. (2013). Social acceptance of low carbon energy and associated infrastructures: A critical discussion. Energy Policy, 58, Amsterdam: Elsevier, pp. 1-5.

Burningham, K. (2000). Using the language of NIMBY: A topic for research, not an activity for researchers. Local Environment, 5(1), Abingdon: Taylor \& Francis, pp. 55-67, DOI:10.1080/135498300113264

Climate and Energy Fund (2014). Climate and energy model regions. An Austrian blueprint for a successful bottom-up approach in the field of climate change and energy. Available at: http://www.klimafonds.gv.at/assets/Uploads/Downloads-Frderungen/KuE -Modellregionen/Fact-Sheet-Climate-and-Energy-Model-Regions.pdf (Accessed: 14 May 2021).

Cohen, J. J., Reichl, J. and Schmidthaler, M. (2014). Re-focusing research efforts on the public acceptance of energy infrastructure: A critical review. Energy, 76,, Amsterdam: Elsevier, pp. 4-9.

Deressa, T. T., Hassan, R. M. and Ringler, C. (2011). Perception of and adaptation to climate change by farmers in the Nile basin of Ethiopia. The Journal of Agricultural Science, 149(1), Cambridge: Cambridge University Press, p. 23.

Devine-Wright, P. (Ed.). (2014). Renewable Energy and the Public: From NIMBY to Participation. London and Washington, DC: Routledge. 
European Commission (2014). Communication from the Commission to the European Parliament and the Council. European Energy Security Strategy. COM (2014) 330 final. European Commission, Brussels, 28.5.2014. Available at: https://eur-lex.europa .eu/legal-content/EN/TXT/PDF/?uri=CELEX:52014DC0330\& from=EN (Accessed: 15 January 2021).

Fosu-Mensah, B. Y., Vlek, P. L. and MacCarthy, D. S. (2012). Farmers' perception and adaptation to climate change: A case study of Sekyedumase district in Ghana. Environment, Development and Sustainability, 14(4), New York: Springer, pp. 495-505. DOI:10.1007/s10668-012-9339-7

Gbetibouo, G. A. (2009). Understanding Farmers' Perceptions and Adaptations to Climate Change and Variability: The Case of the Limpopo Basin, South Africa (Vol. 849). South Africa: International Food Policy Res Institute.

IPCC (2019). Climate Change and Land: An IPCC Special Report on Climate Change, Desertification, Land Degradation, Sustainable Land Management, Food Security, and Greenhouse Gas Fluxes in Terrestrial Ecosystems [P. R. Shukla, J. Skea, E. Calvo Buendia, V. Masson-Delmotte, H.-O. Pörtner, D. C. Roberts, P. Zhai, R. Slade, S. Connors, R. van Diemen, M. Ferrat, E. Haughey, S. Luz, S. Neogi, M. Pathak, J. Petzold, J. Portugal Pereira, P. Vyas, E. Huntley, K. Kissick, M. Belkacemi, J. Malley (eds.)].

Jones, C. R. and Eiser, J. R. (2010). Understanding 'local' opposition to wind development in the UK: How big is a backyard? Energy Policy, 38(6), Amsterdam: Elsevier, pp. 3106-17.

Kaldellis, J., Kavadias, K. and Zafirakis, D. (2013). The role of hydrogen-based energy storage in the support of large-scale wind energy integration in island grids. International Journal of Sustainable Energy, 34(3-4), Abingdon: Taylor \& Francis, pp. 188-201. DOI:10.1080/14786451.2013.84634

Komendantova, N. (2018). Energy transition in the Austrian climate and energy model regions: A multi-risk participatory governance perspective on regional resilience. Procedia Engineering, 212, Amsterdam: Elsevier, pp. 15-21. DOI:10.1016/j. proeng.2018.01.003

Komendantova, N. and Neumueller, S. (2020). Discourses about energy transition in Austrian climate and energy model regions: Turning awareness into action. Energy $\mathbb{E}$ Environment, 31(8) Thousand Oaks: SAGE Publishing. pp. 1473-1497 DOI:10.1177/ $0958305 \times 20907086$

Komendantova, N., Riegler, M. and Neumueller, S. (2018). Of transitions and models: Community engagement, democracy, and empowerment in the Austrian energy transition. Energy Research and Social Sciences, 39, Amsterdam: Elsevier, pp. 141-51.

Lorenzoni, I. and Pidgeon, N. F. (2006). Public views on climate change: European and USA perspectives. Climatic Change, 77(1), New York: Springer, pp. 73-95. DOI:10.1007/s10584-006-9072-z

Maddison, D. (2007). The Perception of and Adaptation to Climate Change in Africa. Washington, DC: World Bank Publications, Vol. 4308.

Manandhar, S., Vogt, D. S., Perret, S. R. and Kazama, F. (2011). Adapting cropping systems to climate change in Nepal: A cross-regional study of farmers' perception and practices. Regional Environmental Change, 11(2), New York: Springer, pp. 335-48.

Mertz, O., Mbow, C., Reenberg, A. and Diouf, A. (2009). Farmers' perceptions of climate change and agricultural adaptation strategies in rural Sahel. Environmental Management, 43(5), New York: Springer, pp. 804-16.

Mirza, U. K., Ahmad, N., Harijan, K. and Majeed, T. (2009). Identifying and addressing barriers to renewable energy development in Pakistan. Renewable and Sustainable Energy Reviews, 13(4), Amsterdam: Elsevier, pp. 927-31. 


\section{Nadejda Komendantova et al.}

Mondal, M. A. H., Kamp, L. M. and Pachova, N. I. (2010). Drivers, barriers, and strategies for implementation of renewable energy technologies in rural areas in Bangladesh - An innovation system analysis. Energy Policy, 38(8), Amsterdam: Elsevier, pp. 4626-34.

Musall, F. D. and Kuik, O. (2011). Local acceptance of renewable energy-A case study from southeast Germany. Energy Policy, 39(6), Amsterdam: Elsevier, pp. 3252-60.

Nkoana, E. M., Waas, T., Verbruggen, A., Burman, C. J. and Hugé, J. (2017). Analytic framework for assessing participation processes and outcomes of climate change adaptation tools. Environment, Development and Sustainability, 19(5), New York: Springer, pp. 1731-60. DOI:10.1007/s10668-016-9825-4

Patt, A. (2015). Transforming Energy: Solving Climate Change with Technology Policy. Cambridge: Cambridge University Press, p. 349.

Rau, I., Schweizer-Ries, P. and Hildebrandt, J. (2012). The silver bullet for the acceptance of renewable energies? In Kabisch, S., Kunath, A., Schweizer-Ries, P. and Steinführer, A. (Eds.), Vulnerability, Risks, and Complexity: Impact of Global Change on Human Habitats, Gottingen: Hogrefe, pp. 177-91.

REN 21 (2019). Renewables 2019. Global Status Report. Paris: REN21. ISBN 978-3-9818911-7-1.

Renn, O. (2008). Coping with Uncertainty in a Complex World, Earthscan. London and Washington, DC: Routledge, p. 455.

Renn, O. (2015). Aspekte der Energiewende aus sozialwissenschaftlicher Perspektive. Analyse aus der Schriftenreihe Energie der Zukunft. Leopoldina, acatech, Union der deutschen Akademien der Wissenschaften, Muenchen, Halle (Saale), Mainz.

Richards, G., Noble, B. and Belcher, K. (2012). Barriers to renewable energy development: A case study of large-scale wind energy in Saskatchewan, Canada. Energy Policy, 42, Amsterdam: Elsevier, pp. 691-8.

Rowe, G. and Frewer, L. (2000). Public participation methods: A framework for evaluation. Science Technology Human Values Winter, 25(1), Thousand Oaks: SAGE Publishing, pp. 3-29. DOI:10.1177/016224390002500101

Salter, J., Robinson, J. and Wiek, A. (2010). Participatory methods of integrated assessment a review. Wiley Interdisciplinary Reviews: Climate Change, 1(5), Hoboken: Wiley-Blackwell, pp. 697-717. DOI:10.1002/wcc.73

Sovacool, B. K. (2009). The cultural barriers to renewable energy and energy efficiency in the United States. Technology in Society, 31(4), Amsterdam: Elsevier, pp. 365-73.

Sovacool, B. K. (2016). How long will it take? Conceptualizing the temporal dynamics of energy transitions. Energy Research and Social Science, 13, Amsterdam: Elsevier, pp. 202-15.

Wolsink, M. (2000). Wind power and the NIMBY-myth: Institutional capacity and the limited significance of public support. Renewable Energy, 21(1), Amsterdam: Elsevier, pp. 49-64.

Wolsink, M. (2006). Invalid theory impedes our understanding: A critique on the persistence of the language of NIMBY. Transactions - Institute of British Geographers, 31(1), Hoboken: Wiley-Blackwell, pp. 85-91. DOI:10.1111/j.1475-5661.2006.00191.x

Wolsink, M. (2012). The research agenda on social acceptance of distributed generation in smart grids: Renewable as common pool resources. Renewable and Sustainable Energy Reviews, 16(1), Amsterdam: Elsevier, pp. 822-35.

Wüstenhagen, R., Wolsink, M. and Burer, M. (2007). Social acceptance of renewable energy innovation: An introduction to the concept. Energy Policy, 35(5), May 2007, Amsterdam: Elsevier. pp. 2683-269. DOI: 10.1016/j.enpol.2006.12.001 
Zillman, D. N., Lucas, A. and Pring, A. (Ed.). (2002). Human Rights in Natural Resources. Oxford: Oxford University Press.

Zoellner, J., Schweizer-Ries, P. and Wemheuer, C. (2008). Public acceptance of renewable energies: Results from case studies in Germany. Energy Policy, 36(11), Amsterdam: Elsevier, pp. 4136-41.

Zografakis, N., Sifaki, E., Pagalou, M., Nikitaki, G., Psarakis, V. and Tsagarakis, K. P. (2010). Assessment of public acceptance and willingness to pay for renewable energy sources in Crete. Renewable and Sustainable Energy Reviews, 14(3), Amsterdam: Elsevier, pp. 1088-95. 
$\Longrightarrow$ Taylor \& Francis Taylor \& Francis Group

http://taylorandfrancis.com 